Arq. Bras. Med. Vet. Zootec., v.65, n.4, p.1049-1056, 2013

\title{
Padronização da técnica de plasmaférese automatizada em equinos
}

[Standardization of automated plasmapheresis in horses]

\author{
P.B. Escodro ${ }^{1}$, J.O. Bernardo ${ }^{2,7}$,E.G. Roveri ${ }^{3}$, L.O. Escodro ${ }^{4}$, C.F. Oliveira ${ }^{2}$, L.S. Fonseca ${ }^{2}$, \\ C.R.A. Lopes ${ }^{1}$, J. Tonholo ${ }^{5}$, T. Gomes do Nascimento ${ }^{6}$ \\ ${ }^{1}$ Universidade Federal de Alagoas (Ufal) - Viçosa, AL \\ ${ }^{2}$ Aluna de graduação (Ufal) - Viçosa, AL \\ ${ }^{3}$ Universidade Estadual de Campinas (Unicamp) - Campinas, SP \\ ${ }^{4}$ Biomédica autônoma \\ ${ }^{5}$ Instituto de Química e Biotecnologia (IQB-Ufal) - Viçosa, AL \\ ${ }^{6}$ Escola de Enfermagem e Farmácia (Esenfar-Ufal) - Viçosa, AL \\ ${ }^{7}$ Bolsista PIBIT-CNPq

\section{RESUMO}

O presente artigo objetivou estudar a viabilidade da técnica de plasmaférese automatizada e padronizá-la em cinco equinos hígidos, bem como apresentar as complicações durante o procedimento, as adequações em relação aos procedimentos em humanos e avaliar a recuperação de volume globular e proteínas plasmáticas totais nos doadores. Os procedimentos foram realizados com o equipamento Fresenius AS104, com duração média de 1 h46min, processamento de $5758 \mathrm{~mL}$ de sangue total e colheita média de $3133 \mathrm{~mL}$ de plasma. Não foram observadas alterações significativas do volume globular após a plasmaférese automatizada. A recuperação dos níveis plasmáticos de proteínas foi de 91,4\% em 96 horas após o procedimento. A plasmaférese automatizada apresentou-se viável para a espécie equina, diminuindo o tempo de recuperação hematimétrica nos doadores.

Palavras-chave: equino, plasmaférese, níveis hematimétricos

\begin{abstract}
This paper aimed to study feasibility and standardize the automated plasmapheresis in five healthy horses, showing the complications during the procedure, adjustments in relation to the procedures in humans and assessing the recovery of globular volume and plasma total proteins in donors. The procedures were performed with the Fresenius AS104 equipment, with an average duration of one hour and forty six minutes, processing $5758 \mathrm{~mL}$ of whole blood and harvest average of $3133 \mathrm{~mL}$ of plasma. There were no significant variations in globular volume after the automated plasmapheresis. The recovery of plasma total proteins was $91.4 \%$ at 96 hours after the procedure. The automated plasmapheresis appeared viable for the equine species, decreasing the time of hematimetric level recovery in donors.
\end{abstract}

Keywords: equine, plasmapherese, hematimetric levels

\section{INTRODUÇÃO}

A plasmaférese consiste na remoção do sangue total de um paciente, estocagem em bolsa de colheita com anticoagulante, separação do plasma e reinfusão manual ou automatizada dos hemocomponentes remanescentes, acelerando a recuperação hematológica dos doadores (Morris, 1987; Marques Jr., 2011).

A utilização experimental da técnica da plasmaférese manual na produção de soros hiperimunes teve início em 1969 na Índia, o que fez, após alguns anos de experimentação e

Recebido em 19 de outubro de 2011

Aceito em 8 de outubro de 2012

E-mail: pierre.vet@gmail.com 
padronização, o método ser introduzido na rotina da produção comercial de soros antitetânicos, antidiftéricos e antivenenos, com a utilização da espécie equina. Porém, a técnica automatizada não é utilizada na rotina de produção de plasma de equinos no Brasil, portanto há apenas alguns relatos do procedimento na literatura (Feige et al., 2003; Santos, 2005).

O plasma fresco ou o fresco congelado têm seu uso indicado para o tratamento de patologias que resultam em hipoproteinemia em equinos e bovinos, quando da necessidade de expansão aguda de volemia; em casos de falha na transferência de imunidade passiva, ou quando se pretende fornecer imunidade específica em equinos (Rhodococcus equi, Salmonella typhimurium) ou bovinos (salmonelose) (Hunt e Moore, 1990; Smith e Sherman, 1994; Durham, 1996; Stoneham, 1997); no tratamento ou prevenção de sangramento em pacientes com deficiências de múltiplos fatores de coagulação, como em casos de doenças hepáticas severas ou de coagulação intravascular disseminada (CID); como adjuvante em peritonites e infecções graves; nos casos de intoxicação por cumarina ou warfarina e em distúrbios hemostáticos congênitos (hemofilia, doença de von Willebrand) (Hunt e Moore, 1990; Santos, 2005).

Os fatores limitantes para o uso terapêutico da plasmaférese referem-se à taxa de substituição do plasma no animal doador, prejuízos hematimétricos na colheita manual, contaminação do produto em sistemas abertos de colheita e presença de eritrócitos no plasma colhido manualmente, com possibilidades de sensibilização imunológica do receptor receptor (Von Bering e Kitasato, 1890; Phillips et al., 1974; McVey e Loan, 1980; Brook, 1989; Magdesian et al., 1992; McLure et al., 2001).

Atualmente as plasmaféreses na espécie equina são realizadas cotidianamente, de forma manual, objetivando a produção de vacinas e soros ou plasmas hiperimunes. Para a obtenção manual do plasma hiperimune, realiza-se a colheita do sangue total do animal, ocorrendo a hemossedimentação após 24 horas da colheita. Nesse momento, os componentes são diluídos em solução fisiológica $0,9 \%$ e reinfundidos no próprio animal. Tal procedimento é repetido, em média, três vezes, com intervalo de 24 horas, durante a execução do protocolo de produção.
Após a sangria de produção e a plasmaférese, os animais ficam em repouso cerca de dois meses em regime extensivo para recuperação hematimétrica, estando, assim, teoricamente aptos à próxima sessão de produção (Parra, 2005).

Objetivou-se com este trabalho: avaliar a viabilidade da plasmaférese automatizada em equinos, com base nos procedimentos realizados em humanos no hemocentro da Unicamp e nos relatados por Feige et al. (2003), considerando-se a recuperação hematimétrica dos doadores; e a padronização da técnica para possível utilização na rotina de colheita de plasma equino no Brasil.

\section{MATERIAL E MÉTODOS}

A pesquisa foi aprovada pelo Comitê de Ética em Pesquisa da Universidade Federal de Alagoas, sob processo $\mathrm{n}^{\mathrm{o}} 23065.003111 / 2011-80$, sendo os procedimentos realizados em ambulatório. Foram selecionados cinco equinos hígidos, dois machos e três fêmeas primíparas, sem raça definida, com peso entre 290 e $360 \mathrm{~kg}$. Todos os animais foram submetidos aos exames diagnósticos de anemia infecciosa equina e mormo, cujos resultados foram negativos.

Os animais doadores submeteram-se previamente à imunização com vacina de encefalomielite tipo leste e oeste (vírus morto) e toxoide tetânico (Equiloid - Fort Dodge Animal Health - Iowa, EUA); rinopneumonite e influenza (Fluvac Innovator EHV 4/1 - Fort Dodge Animal Health - Iowa, EUA) e raiva (Rubivac - Pfizer Saúde Animal - Guarulhos, Brasil). Após 28 dias, reforçaram-se a imunização e os procedimentos realizados após 20 e 22 dias da segunda vacinação, a fim de se atingir o pico da reação imunológica (Holmes et al., 2006).

Amostras sanguíneas foram obtidas para mensuração do hematócrito $(\mathrm{Ht})$ e proteína total (Pt) dos doadores, nos momentos: no momento da imunização (M0), imediatamente anterior à plasmaférese ou pré-plasmaférese (M1); após 24 horas (M2), 48 horas (M3), 72 horas (M4), 96 horas (M5) e 30 dias (M6). O sangue dos doadores foi colhido da veia jugular externa esquerda, com a utilização do sistema Vacutainer (com agulha $25 \times 8 \mathrm{~mm}$ e tubos de vidro siliconizados para colheita a vácuo, com 
capacidade de $5,0 \mathrm{~mL}$, contendo anticoagulante EDTA - ácido etileno diamido tetracético a 15\%) (Becton Dickinson Vacutainer ${ }^{\circledR}$ - BD Diagnostics, Preanalytical Systems - São Paulo, Brasil).

Para cálculo de volume de plasma (em L) a ser colhido por doador, considerou-se o peso do animal multiplicado por $8 \%$, obtendo-se o volume total de sangue circulante. A partir daí, foi realizada a colheita de sangue individual em M1 e calculado o hematócrito de cada doador, calculando-se o total de plasma circulante pela diferença entre o total de sangue $(100 \%)$ e o valor em porcentagem do hematócrito. $\mathrm{O}$ valor obtido foi multiplicado por $20 \%$ (valor médio absoluto de plasma colhido por paciente no Hemocentro da Universidade de Campinas, sem apresentar complicações).

As plasmaféreses automatizadas foram realizadas com equipamento Fresenius Kabi®, modelo AS104 (Fresenius-Kabi Ltda. - Bad Homburg, Germany), acoplando-se o kit PL1 (FreseniusKabi Ltda. - Bad Homburg, Germany), recomendado pelo fabricante para a realização de plasmaféreses e eritrocitoaféreses.

As plasmaféreses foram realizadas em tronco de contenção, não sendo preconizada tranquilização. A veia jugular esquerda foi mantida com agulha 40X16 (Prod. Hospitalares DI - Belo Horizonte, Brasil), denominada via de colheita; e a veia jugular direita com cateter 14G (Nipro Medical Ltda. - Sorocaba, Brasil) representando a via de reinfusão. $\mathrm{O}$ protocolo preconizado iniciou-se com proporção de uma parte de solução anticoagulante (citrato de sódio 20\%) para 12 partes de sangue total processado (1:12). Para diluição e reposição dos hemocomponentes, foi utilizada solução de cloreto de sódio a 0,9\% (Fresenius Kabi Deutschland - Friedberg, Germany).

O kit PL1 foi acoplado ao equipamento AS104 da Fresenius, seguindo as orientações do fabricante descritas no display. Foram acopladas as soluções de citrato de sódio e solução fisiológica e, em seguida, selecionada a função prime, que preencheu os circuitos para evitar a entrada de ar no sistema. Como não é possível adequar os valores de peso e altura programados no equipamento, devido a este ser fabricado para humanos, foram alterados apenas os valores da concentração do anticoagulante e hematócrito (Ht) do animal. Os valores do Ht foram alterados de acordo com o resultado individual em M1.

Ao término da colheita, a bolsa de plasma colhido foi encaminhada imediatamente para o laboratório, onde foi executada a separação do plasma em bolsas estéreis individuais de $500 \mathrm{~mL}$ (Fresenius HemoCare do Brasil Ltda. Itapecerica da Serra, Brasil), por meio de procedimento em capela de fluxo laminar (Filtracom - Valinhos, Brasil). Em seguida, o plasma foi encaminhado para congelamento a $-18^{\circ} \mathrm{C}$. O congelamento permite a preservação dos fatores da coagulação, fibrinólise e complemento, além de albumina, imunoglobulinas, outras proteínas e sais minerais, e mantém constantes suas propriedades.

Para mensuração da proteína total, utilizou-se kit proteínas totais Labtest ${ }^{\circledR}$ (Labtest Diagnóstica S/A - Lagoa Santa, Brasil), em espectrofotômetro Photonics 2000UV (Bel Equipamentos Analíticos Ltda. - Piracicaba, Brasil). O hematócrito foi realizado em centrífuga de micro-hematócrito a 12000rpm (Microspin Gemmico Industrial Corp. - Taiwan, China). Avaliou-se a recuperação plasmática de proteínas totais e dos níveis de eritrócitos e identificou-se uma possível desidratação ou perda de eritrócitos associadas ao procedimento.

$\mathrm{O}$ cálculo dos valores de média aritmética e o desvio-padrão dos resultados obtidos foram determinados utilizando-se o programa de computador ASSISTAT, versão 7.6 beta (Silva e Azevedo, 2009). Para a confirmação das diferenças entre as médias dos momentos da análise clínica, usou-se um teste emparelhado de médias (teste de Friedman).

\section{RESULTADOS E DISCUSSÃO}

O protocolo inicial preconizado, com a utilização da agulha calibre 40x16 para a via de colheita e a proporção de citrato de sódio de 1:12, apresentou duas intercorrências: a primeira foi a não manutenção da veia de colheita com a agulha, tendo que ser manipulada várias vezes, o que causou sensibilidade local e flebite; a segunda foi a coagulação do sangue no cateter de reinfusão, 
impedindo-lhe a fluidez no circuito. Assim, aumentou-se a concentração para 1:10 da solução anticoagulante, porém sem sucesso. Optou-se pela utilização de solução heparinizada na concentração 25 000UI de heparina sódica (HEPAMAX-S® - Blausiegel Ind. e Com. Ltda. - Cotia, Brasil) em 500mL de solução fisiológica $0,9 \%$ diretamente no cateter da via de reinfusão, entretanto tornou-se necessária sua utilização a cada 300mL de plasma colhido, sendo que, por três vezes, ele obstruiu-se.

Essas complicações ocorreram nos dois primeiros doadores, sendo que, a partir do terceiro, utilizou-se cateter $14 \mathrm{G}$ também na veia de colheita do sangue. Em humanos, não são utilizados cateteres pelo risco de colabamento deles e interrupção no fluxo extracorpóreo do equipamento. Além disso, optou-se por aumentar a concentração do anticoagulante citrato de sódio para 1:8, mesmo correndo-se os riscos inerentes ao excesso de anticoagulante nas plasmaféreses, entre eles: parestesia perioral e nos membros, calafrios e hipotensão (Motta, 2007).

Nos últimos três animais não ocorreram intercorrências ou complicações, sendo que, quando foi colhido o volume calculado, fechouse o clamp de colheita e retirou-se o cateter da veia jugular externa esquerda. Nesse momento, foi selecionada a tecla enter para iniciar a reinfusão. Após a total reinfusão dos componentes sanguíneos com a solução de reposição, o clamp de reinfusão foi fechado, o cateter retirado e foi selecionada a tecla stop.

No procedimento do doador 1, as duas complicações citadas levaram à flebite na veia jugular direita (reinfusão) devido à excessiva manipulação durante a padronização da técnica. Com o objetivo de não perder o kit, optou-se por puncionar a veia cefálica direita com cateter $18 \mathrm{G}$.

Após 24 horas do procedimento, os doadores 1 e 2 apresentaram sinais de flebite jugular esquerda, devido à manipulação da agulha 40X16, sendo realizadas massagens locais com pomadas heparinoides (Trombofob®Gel - Heparina sódica 200UI - Knoll Prods. Químs. e Farms. Ltda. - Rio de Janeiro, Brasil).
Os animais mantiveram-se bem durante os procedimentos, sendo que, quando se apresentavam impacientes, foram fornecidas pequenas quantidades de ração para mantê-los calmos.

Em medicina, são relatadas algumas manifestações anafiláticas leves ou severas, tais como prurido, pápulas, inchaço nos olhos, blefaroespasmo, lacrimejamento, tosse seca, falta de ar e estertores nas vias aéreas (Marques Jr., 2011), porém não foi observada nenhuma reação anafilática neste experimento. Também são citados com frequência casos de hipocalcemia com sintomatologia essencialmente neuromuscular, como parestesias, laringoespasmo, broncoespasmo, tremores e convulsões (Durham, 1996; Feige et al., 2003), devido à utilização do citrato de sódio como anticoagulante, não sendo indicada a concentração maior que $1: 10$. Nos equinos, não foi observada nenhuma reação ao anticoagulante utilizado na concentração 1:8.

Apenas o doador 4 apresentou níveis de proteínas totais $(\mathrm{Pt})$ menor que o indicado para a espécie em 24 horas após a colheita. Todos os animais apresentaram índices de Pt normais para a espécie a partir de 48 horas da colheita. Os animais apresentaram valores hematimétricos normais para a espécie em M2 e aumento progressivo desses valores nos três primeiros dias (M4) após a colheita do plasma (Tab. 1 e Fig. 1).

Angulo et al. (1997) avaliaram que o valor do hematócrito aumentava após a plasmaférese, devido à hemoconcentração, sendo os pacientes estabilizados após hidratação dos equinos, porém não foi evidenciado esse fato na pesquisa.

Segundo Pardini (2011), os valores de referência de proteínas totais e fracionadas do plasma são de 5,2 a 7,9g/dL de proteínas totais, 2,6 a $3,7 \mathrm{~g} / \mathrm{dL}$ de albumina e 2,6 a $4,0 \mathrm{~g} / \mathrm{dL}$ de globulinas. Utilizando-se a frequência relativa dos valores absolutos, calculou-se a porcentagem relativa, obtendo-se $50,38 \%$ de globulina e $48,09 \%$ de albumina. Observou-se um aumento significativo médio de $56,56 \%$ da proteína total em M1 em relação à M0 (Tab. 2). 
Tabela 1. Valores médios (X) e desvio-padrão (S) do hematócrito (Ht) dos equinos nos momentos: M0= antes da imunização, M1=pré-plasmaférese; M2= 24 horas após; M3= 48 horas após; M4= 72 horas após; M5= 96 horas após e M6= 30 dias após

\begin{tabular}{ccccccccc} 
Animal & M0 & M1 & M2 & M3 & M4 & M5 & M6 & $\begin{array}{c}\text { Média } \pm \\
\text { desvio-padrão }\end{array}$ \\
\hline $\mathbf{1}$ & 32 & 35 & 30 & 32 & 34 & 34 & 36 & $33.5 \pm 2.16$ \\
$\mathbf{2}$ & 28 & 34 & 34 & 35 & 32 & 30 & 34 & $33.16 \pm 1.83$ \\
$\mathbf{3}$ & 30 & 34 & 30 & 31 & 33 & 32 & 28 & $31.33 \pm 2.16$ \\
$\mathbf{4}$ & 29 & 35 & 31 & 32 & 29 & 34 & 38 & $33.16 \pm 3.18$ \\
$\mathbf{5}$ & 33 & 40 & 40 & 42 & 40 & 38 & 38 & $38.0 \pm 3.09$ \\
$\begin{array}{l}\text { Média } \\
\text { desvio- } \\
\text { padrão }\end{array}$ & $30.4 \pm 2.07$ & $35.6 \pm 2.50$ & $33 \pm 4.24$ & $34.4 \pm 4.50$ & $33.6 \pm 4.03$ & $33.6 \pm 2.96$ & $34.8 \pm 4$ & .14 \\
\hline
\end{tabular}

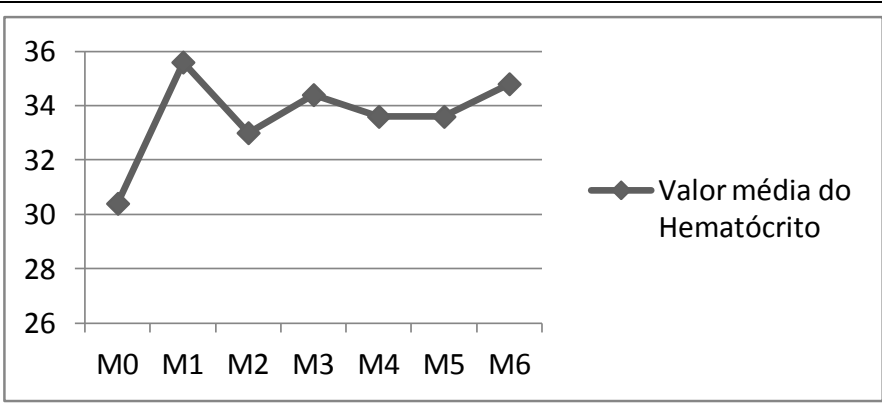

Figura 1. Variação das médias aritméticas dos valores dos hematócritos dos equinos nos momentos: M0= antes da vacinação, M1=pré; M2= 24 horas após; M3= 48 horas após; M4= 72 horas após; M5= 96 horas após e M6= 30 dias após.

Tabela 2. Variação da proteína total dos equinos entre $\mathrm{M} 0=$ antes da imunização e $\mathrm{M} 1=$ pré-plasmaférese

\begin{tabular}{cccc}
\hline Animal & M0 & M1 & M1-M0/M0 \\
\hline 1 & 5,6 & 9,2 & $64,28 \%$ \\
2 & 5,4 & 8,2 & $51,85 \%$ \\
3 & 5,8 & 8,3 & $43,10 \%$ \\
4 & 5,2 & 8,1 & $55,76 \%$ \\
5 & 5,4 & 9,1 & $68,51 \%$ \\
Média \pm desvio- & $5,48 \pm 0,22$ & $8,58 \pm 0,52$ & $56,56 \%$ \\
padrão & & & \\
\hline
\end{tabular}

Magdesian et al. (1992) constataram hemoconcentração e aumento do teor de proteínas totais em equinos submetidos à plasmaférese manual, causada por deficiência na re-hidratação dos animais, não sendo observada no experimento realizado.

A plasmaférese automatizada mostrou-se mais eficaz que a forma manual tradicional. Houve emparelhamento de M1 e M6 e constatou-se que os animais, nos 30 dias após o procedimento, apresentavam concentrações similares de proteínas totais séricas em relação ao momento pré-plasmaférese (Tab. 3). Entre M2 e M3 não houve variação significativa. Mesmo não havendo emparelhamento de dados entre M2 e M5, as médias estão muito próximas, e em M5 a média está dentro do valor de referência máximo para proteína total ( Fig. 2). Na frequência dos valores absolutos, em M5 os equinos já apresentavam, em média, $91,4 \%$ da proteína total sérica inicial (M1). 
Tabela 3. Valores médios (X) e desvio-padrão $(\mathrm{S})$ da proteína total dos equinos nos momentos: $\mathrm{M} 0=$ antes da vacinação, M1=pré; M2= 24 horas após; M3= 48 horas após; M4= 72 horas após; M5= 96 horas após e M6= 30 dias após

\begin{tabular}{|c|c|c|c|c|c|c|c|}
\hline \multirow[b]{2}{*}{ Animal } & \multicolumn{7}{|c|}{ Proteína total $(\mathrm{g} / \mathrm{dL})$} \\
\hline & M1 & M2 & M3 & M4 & M5 & M6 & $\begin{array}{l}\text { Média } \pm \text { desvio- } \\
\text { padrão }\end{array}$ \\
\hline 1 & 9,2 & 6,8 & 6,3 & 6,8 & 7,2 & 8,4 & $7,45 \pm 1,11$ \\
\hline 2 & 8,2 & 7,2 & 7,3 & 7,8 & 8,4 & 8,4 & $7,88 \pm 0,53$ \\
\hline 3 & 8,3 & 6,5 & 6,8 & 7,8 & 7,8 & 8,8 & $7.66 \pm 0,87$ \\
\hline 4 & 8,1 & 5,2 & 6,5 & 7,2 & 7,6 & 8,8 & $7.23 \pm 1,26$ \\
\hline 5 & 9,1 & 7,1 & 7,4 & 7,8 & 8,2 & 8,8 & $8.06 \pm 0,6$ \\
\hline $\begin{array}{c}\mathrm{X} \pm \mathrm{S} \\
(\%)\end{array}$ & $8,58 \pm 0,52$ & $6,56 \pm 0,8$ & $6,86 \pm 0,48$ & $7,48 \pm 0,46$ & $7.84 \pm 0,47$ & $8,64 \pm 0,21$ & $7.66 \pm 0,86$ \\
\hline $\begin{array}{c}\text { relação } \\
\text { ao M1 }\end{array}$ & & $76,45 \%$ & $79,95 \%$ & $87,17 \%$ & $91,37 \%$ & $100,6 \%$ & \\
\hline
\end{tabular}

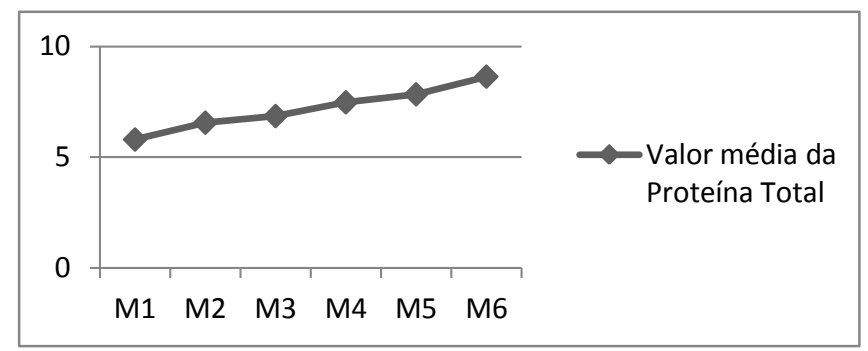

Figura 2. Variação das médias aritméticas dos valores da proteína total dos equinos nos momentos: M1=pré; M2= 24 horas após; M3= 48 horas após; M4= 72 horas após; M5= 96 horas após e M6= 30 dias após.

O procedimento automatizado foi realizado com média e desvio-padrão de 1 h46min $\pm 25 \mathrm{~min}$, próximo à duração do procedimento em humanos (em média, duas horas), com o processamento médio de 5,75860 $\pm 0,87688$ litros de sangue e colheita de 3,13340 $\pm 0,50610$ litros de plasma de cada animal ( Tab. 4).
Nos animais 1 e 2 não foi possível a colheita do volume de plasma esperado, devido às complicações relatadas, que resultaram na substituição da agulha para cateter na via de colheita e no aumento da concentração de anticoagulante no sistema extracorpóreo (1:8).

Tabela 4. Tempo de duração, quantidade de sangue processado, plasma colhido, quantidade de fluido de reposição (cloreto de sódio 0,9\%) utilizados durante o procedimento de plasmaférese de equinos

\begin{tabular}{ccccc} 
Animal & $\begin{array}{c}\text { Tempo de } \\
\text { duração } \\
(\mathrm{h})\end{array}$ & $\begin{array}{c}\text { Quantidade de sangue } \\
\text { processado } \\
(\mathrm{L})\end{array}$ & $\begin{array}{c}\text { Quantidade de } \\
\text { plasma colhido } \\
(\mathrm{L})\end{array}$ & $\begin{array}{c}\text { Quantidade de } \\
\text { fluido de } \\
\text { reposição (L) }\end{array}$ \\
\hline 1 & 2 h30min & 4,313 & 2,580 & 1,5 \\
2 & $1 \mathrm{~h} 40 \mathrm{~min}$ & 6,350 & 2,578 & 1,6 \\
3 & $1 \mathrm{~h} 30 \mathrm{~min}$ & 5,859 & 3,502 & 1,3 \\
4 & $1 \mathrm{~h} 30 \mathrm{~min}$ & 5,722 & 3,505 & 1,2 \\
5 & $1 \mathrm{~h} 40 \mathrm{~min}$ & 6,549 & 3,502 & 1,5 \\
$\mathrm{X}$ & $1 \mathrm{~h} 46$ min $\pm 25 \mathrm{~min}$ & $5.75860 \pm 0.87688$ & $3.13340 \pm 0.50610$ & $1.42 \pm 0.1643$ \\
\hline
\end{tabular}


As vantagens da plasmaférese automatizada em relação à manual foram: representa um processo extremamente estéril que influi na maior qualidade do produto final e nos menores riscos de pirogenia (Marques Jr., 2011); mostrou-se tão eficaz quanto o procedimento manual, tendo como diferencial que a colheita pode ser realizada em uma única etapa e o volume sanguíneo processado representa 38,39\% do valor citado por Parra (2005). A única desvantagem é o custo dos kits e o aluguel do equipamento, que tornam o procedimento mais oneroso, porém o mercado deve absorver tecnologias de hemoterapia mais dispendiosas, buscando sanar afecções em que as plasmaféreses apresentem indicação terapêutica.

\section{CONCLUSÃO}

A plasmaférese automatizada apresentou-se como alternativa viável na espécie equina, podendo ser utilizada na produção de plasma hiperimune, na produção de vacinas contra diversas doenças e até mesmo na produção de soro antiofídico.

\section{AGRADECIMENTOS}

Os autores agradecem ao Conselho Nacional de Desenvolvimento Científico e Tecnológico (CNPq), pela concessão de Bolsa PIBIT; ao Hemocentro da Unicamp, à Pró-Reitoria de Pesquisa e Pós-Graduação - UFAL, a FreseniusKabi e à Guabi Nutrição Animal, pela parceria e viabilização deste experimento junto ao Grupo de Pesquisa e Extensão em Equídeos - UFAL

\section{REFERÊNCIAS}

ANGULO, Y.; ESTRADA, R.; GUTIÉRREZ, J.M. Effects of bleeding in horses immunized with snake venoms for antivenom production. Rev. Biol. Tropical, v.45, p.1215-1221, 1997.

BROOK, D. Aspects of plasma production. Equine Vet. Sci., v.8, p.303-306, 1989.

DURHAM, A.E. Blood and plasma transfusion in the horse. Equine Vet. Educ., v.8, p.8-12, 1996.

FEIGE, K.; EHRAT, F.B.; KASTNER, S.B.R. et al. Automated Plasmapheresis compared with other plasma collection methods in the horse. $J$. Med. Vet., v.50, p.185-189, 2003.
HOLMES, M.A.; TOWNSEND, H.G.G.; KOHLER, A.K. et al. Immune responses to commercial equine vaccines against equine herpesvírus-1, equine influenza virus, eastern equine encephalomyelitis, and tetanus. Vet. Immunology and Immunopathology, v.111, p.6780, 2006.

HUNT, E.; MOORE, J.S. Use of blood and blood products. Vet. Clin. North Am. Food Anim. Pract., v.6, p.133-147, 1990.

MAGDESIAN, K.G.; BROOK, D.; WICKLER, S.J. Temporal effects of plasmapheresis on serum proteins in horses. Am. J. Vet. Res., v.53, p.1149-1153, 1992.

MARQUES Jr., J.F.C. Hemaféreses terapêuticas. Campinas: Hemocentro Universidade Estadual de Campinas. Disponível em: http://www.google.com.br/url?sa=t\&source=web $\& c d=21 \& v e d=0$ CBkQFjAAOBQ \&url=http $\% 3 \mathrm{~A}$ $\% 2 \mathrm{~F} \% 2 \mathrm{Fforuns}$.bc.unicamp.br\%2Fsaude $\% 2 \mathrm{Feve}$ nto $12 \% 2$ Fmarques.ppt\&rct=

j\&q=af\%C3\%A9rese\%20terap\%C3\%AAutica\&e $\mathrm{i}=\mathrm{W} 6 \mathrm{kxTYCZPIbMgQfTr} \_T E C w \& u s g=A F Q j C$ NFAUog5k0901GGUNcBPSzYH07bUlA\&cad= rja. Acessado em: 15 jan. 2011.

McLURE, J.T.; DELUCA, J.L.; LUNN, D.L. et al. Evaluation of $\mathrm{IgG}$ concentration and $\mathrm{IgG}$ subisotypes in foals with complete or partial failure of passive transfer after administration of intravenouns serum or plasma. Equine Vet. J., v.33, p.681-686, 2001.

McVEY, S.; LOAN, R.W. Total and antigenspecific serum immunoglobulin isotype concentrations in hyperimmunized cattle that have undergone plasmapheresis. Am. J. Vet. Res., v.50, p.758-761, 1989.

MORRIS, D.D. Blood products in large animal medicine: a comparative account of current and future technology. Equine Vet. J., v.19, p.272275, 1987.

MOTTA, I. Aférese terapêutica. In: VII Curso de Educação Médica Continuada, 2007. Disponível em:

http://www.cremerj.org.br/palestras/506.PDF Acessado em: 3 ago. 2011. 
PARDINI, H. Manual de Bioquímica Veterinária. Belo Horizonte: Instituto Hermes Pardini Veterinária. Disponível em: http://pt.scribd.com/doc/61465262/MANUALBIOQUIMICA-VET Acessado em: 27 set. 2011.

PARRA, A.C. Variações da crase sanguínea durante a hiperimunização e após sangria $e$ plasmaférese em equinos de produção de soro hiperimune anti-crotálico. 2005. 134f. Dissertação (Mestrado em Medicina Veterinária) - Faculdade de Medicina Veterinária e Zootecnia, Universidade de São Paulo, São Paulo.

PHILLIPS, A.W.; COURTENAY, J.S.; RUSTON, R.D.H. et al. Plasmapheresis of horses by extracorporal circulation of blood. Res. Vet. Sci., v.16, p.35-39, 1974.

SANTOS, R.B. Influência do uso de plasmaférese sobre o tempo de recuperação de caprinos doadores de sangue ou plasma. 2005, 125p. Dissertação (Mestrado em Medicina Veterinária) - Faculdade de Medicina Veterinária e Zootecnia, Universidade de São Paulo, São Paulo.
SILVA, F.A.S.; AZEVEDO, C.A.V. Principal Components Analysis in the Software AssistatStatistical Attendance. In: WORLD CONGRESS ON COMPUTERS IN AGRICULTURE, 7., 2009. Reno-NV-USA: American Society of Agricultural and Biological Engineers, 2009.

SMITH, M.C.; SHERMAN, D.M. Blood, lymph and immune systems. In: SMITH, M.C.; SHERMAN, D.M. Goat medicine. Philadelphia: Lea\&Febiger, 1994. p.193-230.

SOUZA NETTO, B.A. Valores de referência hemograma equino. Rio de Janeiro: Laborfife veterinária. Disponível em: http://www.laborlife.com.br /exames/ hematoref. html.Acessado em: 12 ago. 2011.

STONEHAM, S. Collection and administration of plasma to a newborn foal. In Practice, v.19, p.384-385, 1997.

VON BERING, E.; KITASATO, S. Ueber das Zustandekommen der Diphtherie-immunitãt und der Tetanus-immunitãt bei Thieren. Deutsche Med. Wochenschrift, v.16, p.1113-1145, 1890. 